\title{
Identifying payments for ecosystem services participants through social or spatial targeting? Exploring the outcomes of group level contracts
}

\author{
Francesca L. McGrath ${ }^{1,2}$ (1) | Beria Leimona ${ }^{3}$ | Sacha Amaruzaman ${ }^{3}$ | \\ Nana P. Rahadian ${ }^{4}$ | Luis R. Carrasco'
}

\author{
${ }^{1}$ Department of Biological Sciences, \\ National University of Singapore, Singapore \\ ${ }^{2}$ School for Environment and Sustainability, \\ University of Michigan, Ann Arbor, \\ Michigan \\ ${ }^{3}$ World AgroForestry Center (ICRAF), JL, \\ CIFOR, Bogor, Indonesia \\ ${ }^{4}$ Rekonvasi Bhumi, Serang, Indonesia

\section{Correspondence} \\ Francesca L. McGrath, Department of \\ Biological Sciences, National University of \\ Singapore, 14 Science Drive 4, 117543, \\ Singapore. \\ Email: fmcgrath@umich.edu

\section{Funding information} \\ Singapore International Graduate Award \\ (SINGA); Rufford Small Grant for Nature \\ Conservation
}

\begin{abstract}
Participants in payments for ecosystem services (PES) schemes can be identified in numerous ways, for example, through social or spatial targeting. However, little is known about how the type of participant targeting will influence the PES outcomes. Using a longstanding PES scheme in Cidanau Indonesia, we evaluate the outcomes of using social and spatial participant identification. The outcomes compared are participant perceptions of equity, understanding, and compliance. This scheme contracts farmers at the group level and has had two implementation phases, the first contracted farmers based on social relationships and the second based on spatial proximity of their plots to reduce monitoring costs. We find that both the social and spatial targeting of participants is perceived as fair, and all participants are complying. Our results thus suggest that the perceived trade-off between efficiency and equity is not ubiquitous and that efficiency gains were made without compromising compliance and perceived equity. We also find that training for the farmer group (FG) leaders is crucial in ensuring that the rest of the FG members understand the PES scheme and its requirements.
\end{abstract}

\section{K E Y W O R D S}

efficiency, equity, Indonesia, participation, payments for ecosystem services

\section{1 | INTRODUCTION}

Payments for ecosystem services (PES) are a widely implemented instrument for environmental conservation. How participants are identified and at what level they are contracted is one of the first crucial steps in a scheme's implementation process. Due to the variability in PES implementation, there are common concerns about participation in PES regarding additionality (Kerr, Vardhan, \& Jindal, 2014), whether participation is voluntary (Börner et al.,
2017), and the motivations to participate (Fisher, 2012). Within this paper, we explore two types of participant identification, comparing social and spatial targeting, across a group-level contract in a PES scheme in Indonesia.

Organizers can identify how people participate in many ways, for example targeting by spatial factors or targeting by social connections. Spatial targeting, the process of identifying PES participants based on some spatial factor (e.g., proximity to other participants, areas of high carbon stock) can allow for multiple benefits to be achieved in an

This is an open access article under the terms of the Creative Commons Attribution License, which permits use, distribution and reproduction in any medium, provided the original 
efficient manner, for instance through reducing transport costs involved in monitoring (de Koning et al., 2011). Wünscher, Engel, and Wunder (2008) found that using spatial targeting increased the efficiency of a PES scheme in Costa Rica but they further argued that this targeting failed to consider the non-monetary values of landowners (e.g., conservation preferences). This, in turn, could influence participation. Furthermore, identifying areas that are more under threat, with higher service provision and lower costs can improve PES results, specifically with regard to carbon storage (Angelsen et al., 2009). Selecting participants based on their social relations, for example contracting farmers in pre-existing groups has potential implications. In some cases, it may be more efficient whereby high levels of trust can help increase participation (Zanella, Schleyer, \& Speelman, 2014). However, despite the apparent gains for each participant selection type, currently, little research has been completed comparing the outcomes of using either a social or spatially targeted selection processes.

Participants can be contracted at the individual, group or community level. Communities that have shared resources may prefer a community-level contract. For example, it was found that forest-based communities are more likely to have shared resources and subsequently have benefits distributed at the community level (Mahanty, Suich, \& Tacconi, 2013). However, being contracted at the community level may not reflect all the preferences at the individual level, whereby some community members may not be active members in the decision-making process (Murtinho \& Hayes, 2017). It is also possible that within these collective groups, the preferences for the PES will only represent the leader rather than the group's best interest. For example, the preferences of the poorer or more marginalized individuals may be overlooked (Murtinho \& Hayes, 2017; Sommerville, Milner-Gulland, Rahajaharison, \& Jones, 2010). Furthermore, there is a current literature gap in how participants will perceive grouplevel targeting both socially and spatially. Achieving a well-informed fair collective decision can take time as individuals within the community need to access information and build a consensus (Agrawal \& Ostrom, 2001; Ostrom, 1990). A key aspect to guarantee equitable participation in PES may thus lie in preventing power dominance by single individuals and creating or using existing platforms for consensus building. An already established institution within a community can aid in the implementation and subsequent participation of a PES scheme at the community level (Hayes \& Murtinho, 2018; Kosoy, Corbera, \& Brown, 2008). For example, a community with a preexisting natural resource management institution may be more likely to participate in the scheme (Bremer, Farley, \& Lopez-Carr, 2014). The sellers of the ES are a vital component of PES as their views and opinions have the ability to determine if the scheme is successful (Petheram \& Campbell, 2010). If stakeholders do not consider the PES socially legitimate, it may be unsuccessful in obtaining its desired environmental objectives.

Building on this, little is known about what type of targeting will increase participants' compliance in a scheme. If individuals contracted into a PES do not comply, the scheme risks not achieving its intended outcomes, both social and ecological. Many different factors influence an individual's decision to comply with their respective PES contract. For example, compliance may be influenced by benefits-the payments are enough to cover the individual's opportunity costs-or by social pressure to comply (e.g., with group level contracts [Narloch, Drucker, \& Pascual, 2017]). Efficiency is defined as achieving the PES objective at the lowest cost, whereas equity is discussed through the distribution of costs and benefits, often using the term "pro-poor" (Martin, Gross-Camp, Kebede, \& McGuire, 2014). PES schemes focusing solely on efficiency, such as those that rely on spatial targeting, can potentially generate trade-offs with equity that may be detrimental. For example, placing more emphasis on efficiency over equity increases the risk of civil unrest as inequalities grow. Perceived unfairness and inequities can lead to inefficient outcomes undermining collective behavior and increasing the chances of negative behavior (Martin, Gross-Camp, Kebede, McGuire, \& Munyarukaza, 2014). This can, in turn, lead to other issues such as leakage and to threaten the permanence of the PES scheme at hand (Jost \& Gentes, 2014). Giving equity and efficiency an equal weighting within a scheme can, therefore, garner positive results (Leimona, van Noordwijk, de Groot, \& Leemans, 2015; Pascual et al., 2014). Despite the perceived common notion of the trade-off between equity and efficiency in PES, the actual implications of spatial versus social targeting of participants on this trade-offs are poorly studied.

Non-compliance can also be influenced through a multitude of other reasons, some of which may be compounding. For example, if a scheme is inequitable or if an individual does not understand the contract they may not comply. Ensuring that participants understand the contract by giving information is key for the success of the program at hand. As such, proponents of the scheme have been said to be the most important source of information to participants (Angelsen, Brockhaus, Sunderlin, \& Verchot, 2012). However, within group-level contracts, this task will often fall with the leader of the group to effectively and accurately disseminate information to the other members. For instance, strong leadership was found to be the most important aspect attributed to the success of fisheries management (Gutiérrez, Hilborn, \& Defeo, 2011). In addition, being contracted at the group level may lead to increased compliance and 
achievement of objectives, due to group cohesiveness and social influence (Abrahamse \& Steg, 2013). Importantly, collective contracting can allow for more communication and information sharing between participants (Narloch et al., 2017), which in turn can increase cohesion and achievement of the environmental outcomes.

Given current gaps in the literature, in this paper, we aim to investigate the outcomes of two phases of a PES implementation (social and spatial targeting) of group contracted farmers using multiple factors (fairness, compliance, and understanding/information) focusing on a scheme in the Cidanau watershed, Indonesia. This PES scheme has had two distinct implementation phases. Phase A was based on the NGOs (Rekonvasi Bhumi) relationship with the farmer groups (FGs) and their track record in a previous conservation program and phase $\mathrm{B}$ was based on the spatial proximity of the PES plots. The implementation changed to increase the schemes efficiency via reducing transport costs in plot monitoring and compliance checking. We have three core objectives in this paper. First, we compare fairness and levels of compliance between both implementation phases.
Our hypothesis is that the efficiency gains in Phase B were obtained at the expense of lower fairness and compliance. Second, we compare the understanding and information sources of the scheme between the two phases. Third, we explore the group-level contract and group cohesiveness across both phases, hypothesizing that the more efficient scheme will present less cohesiveness. This case study allows for a unique insight into how PES outcomes may change when identifying participants at the group level using different targeting strategies.

\section{2 | THE CIDANAU PES SCHEME}

\section{1 | Site information}

The Cidanau watershed is approximately 22,036 ha and located within the Banten province of Western Java (Figure 1). Approximately 4,488 ha of land has been selected as critical land areas of conservation priority. Cidanau contains six sub-districts and 60 villages, with most of the population working in the agricultural sector. The
FIGURE 1 Map of Cidanau and location of payments for ecosystem services villages. A, Kadubeureum; B, Ramea; C, Kadu Kempong; D, Cikumbueun; E, Panjangjaya; F, Cisitu; G, Citaman. Source: ICRAF

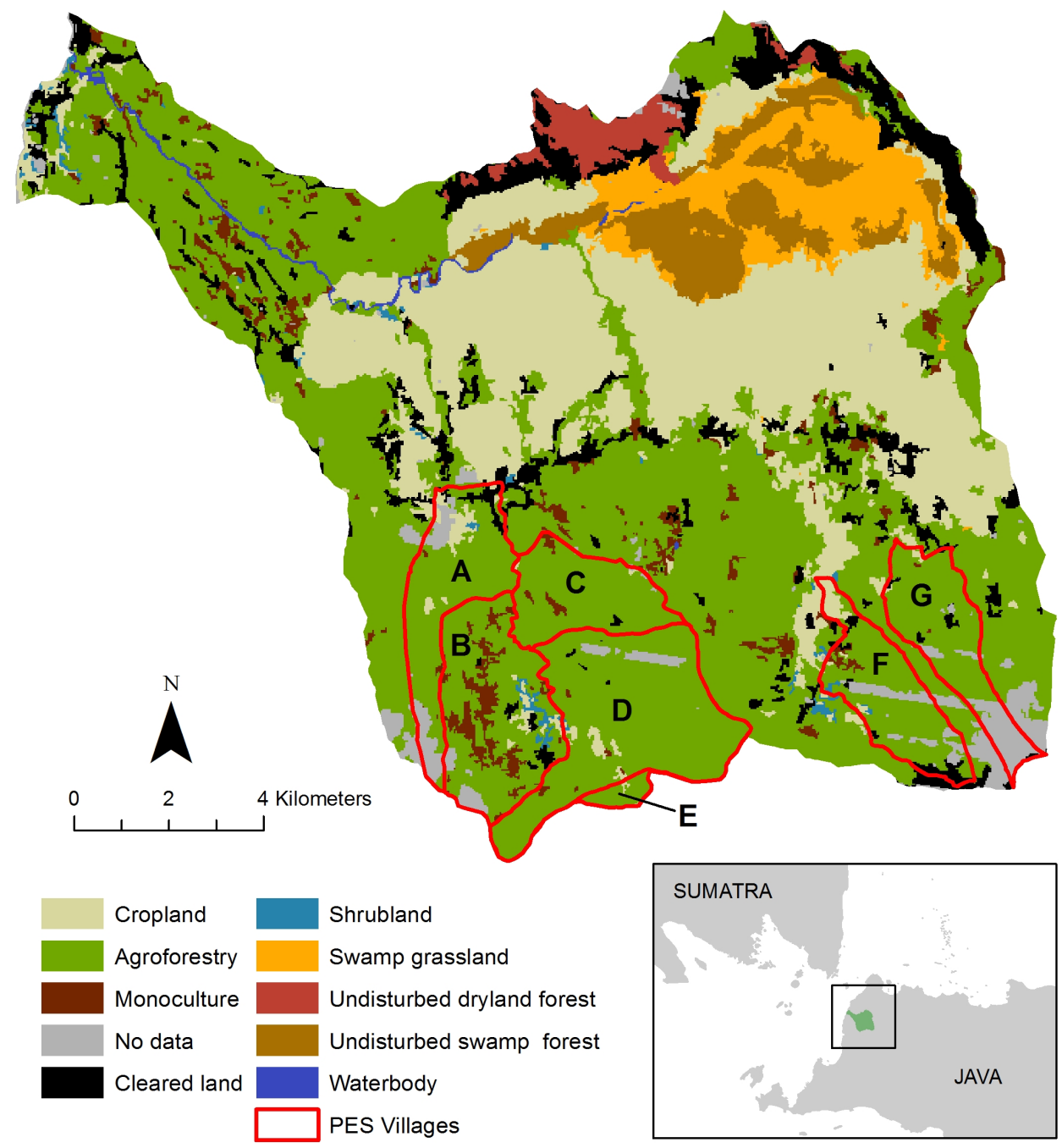


watershed is one of the most important hydrological systems in West Java as it supplies the water for domestic and industrial consumption in the Banten Province and acts as a reservoir for the Cidanau River. One area of particular importance is the Rawa Danau Nature Reserve, which lies at the bottom of the bowl-shaped watershed. The population of this area, particularly in the rural upland areas, are predominantly agroforestry farmers who depend on their land to sustain their existing livelihoods. Extensive farming and agricultural encroachment have led to a decrease in forest cover and watershed services throughout the landscape. Particularly around the Rawa Danau Nature Reserve.

Community-level programs are common throughout Indonesia in both rural and urban settings and are headed by the village chief (Okten \& Osili, 2004). Throughout the Cidanau watershed, many villages have been the target of agricultural conservation programs. However, these have been met with limited success due to the limited attention given to social issues (Leimona, Pasha, \& Rahadian, 2010). As farming is the main occupation, most farmers are organized into FGs. These groups were established to provide a forum for farmers to communicate and share experiences across members, increase incomes and in some cases allow for a stronger bargaining position to vendors. Historically there has been one established FG per village, however, over the past few decades, the number of FGs per village has been increasing. These FGs will have a leader who is usually chosen by a group consensus. The groups will often consist of other members appointed as a secretary or accountant.
Given the multifaceted environmental problems surrounding the Cidanau watershed numerous efforts have been taken to improve the environmental conditions, however, these were met with limited success. In 2005, a PES scheme was implemented with the focus of preserving the forest cover and rehabilitating the critical land areas. This smallscale PES scheme is similar to other schemes throughout Asia and participants are contracted at the group level.

\subsection{Intermediary and funding}

Watershed management in Indonesia is a complicated process involving numerous interests from different actors, making the negotiation process of managing a watershed difficult and time-consuming (Arifin, 2005; Budhi, Sa, \& Iqbal, 2016). The FKDC (Forum Komunikasi DAS Cidanau) consists of a local NGO (Rekonvasi Bhumi), government offices (i.e., forestry and agriculture department, planning office), and various governors/officers (i.e., governor of Banten Province, secretary general of Banten). The FKDC provides management and guidance of the PES in the Cidanau watershed (Figure 2). The funder's of the PES scheme are a water company (KTI) and a chemical company (Asahimas) downstream.

\section{3 | Selection of the PES area and participants}

The PES scheme has had two distinct implementation phases (Table 1). Intermediaries in phase A (2005-2015) targeted

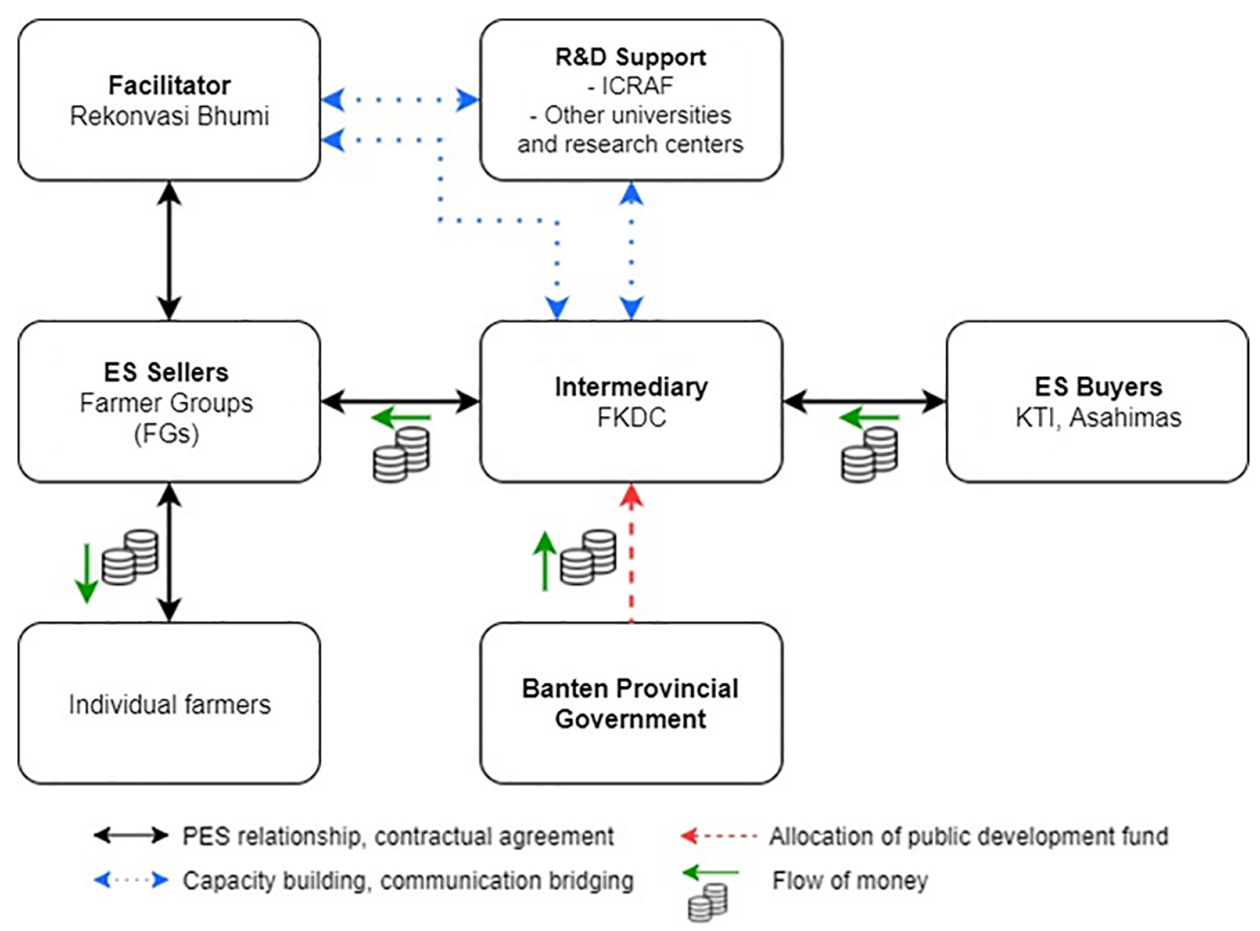

F I G URE 2 Illustrative diagram of the Cidanau payments for ecosystem services program and flow of money. Source: Adapted from Leimona, Pasha, and Rahadian (2010) 
TA B LE 1 Description of the payments for ecosystem services implementation

\begin{tabular}{|c|c|c|}
\hline & Social (phase A) & Spatial (phase B) \\
\hline Contract duration & $2005-2015$ & $2015-2019$ \\
\hline $\begin{array}{l}\text { Contract payment } \\
\text { (USD) } \\
\text { (ha/year) }\end{array}$ & $\$ 120$ & $\$ 135$ \\
\hline $\begin{array}{l}\text { Land } \\
\text { identification }\end{array}$ & $\begin{array}{l}\text { 1. Sedimentation } \\
\text { vulnerable area } \\
\text { 2. High deforestation } \\
\text { rates } \\
\text { 3. Private property } \\
\text { located nearby the } \\
\text { settlement/village }\end{array}$ & $\begin{array}{l}\text { 1. Upstream areas of } \\
\text { the Cidanau } \\
\text { watershed } \\
\text { 2. Outside of the state } \\
\text { forest, } \\
\text { conservation } \\
\text { forest, settlement } \\
\text { and paddy field } \\
\text { areas } \\
\text { 3. Slope needed to be } \\
\text { above } 15 \% \\
\text { 4. } 200 \mathrm{~m} \text { above sea } \\
\text { level } \\
\text { 5. Village areas are at } \\
\text { least } 50 \text { ha in size }\end{array}$ \\
\hline $\begin{array}{l}\text { Group land } \\
\text { requirements }\end{array}$ & 25 ha in total & $\begin{array}{l}25 \text { ha of land must be } \\
\text { spatially proximate } \\
\text { to each other } \\
\text { (contiguous) }\end{array}$ \\
\hline $\begin{array}{l}\text { Group } \\
\text { identification }\end{array}$ & $\begin{array}{l}\text { At the discretion of } \\
\text { local NGO }\end{array}$ & $\begin{array}{l}\text { Complete proposal for } \\
\text { local NGO } \\
\text { including: } \\
\text { 1. The organization } \\
\text { structure of their } \\
\text { farmer groups } \\
\text { 2. Their land } \\
\text { management and } \\
\text { conservation plan } \\
\text { 3. The } \\
\text { benefit-sharing } \\
\text { plan }\end{array}$ \\
\hline $\begin{array}{l}\text { Group } \\
\text { composition }\end{array}$ & $\begin{array}{l}\text { Pre-existing farmer } \\
\text { groups }\end{array}$ & $\begin{array}{l}\text { Farmer groups created } \\
\text { and/or amended to } \\
\text { fulfill the contiguous } \\
\text { land requirement }\end{array}$ \\
\hline
\end{tabular}

PES locations based on three land requirements factors and the selection of FGs was based on the subjectivity of the intermediaries (Lapeyre, Pirard, \& Leimona, 2015). The contracted FGs faced no other requirements to their inclusion and were based on the NGOs relationship with the FGs and their track record in a previous conservation program. The previous programs to improve the watersheds quality included a transmigration program, reforestation and land rehabilitation activities (Leimona, Pasha, \& Rahadian, 2010). Phase B (2015-2019), with the help of ICRAF, selected groups based on a developed map of key areas
(Amaruzaman, Rahadian, \& Leimona, 2017). Based on these five factors 3,360 ha of land and 30 candidate villages were identified.

A core difference between phase A and B is that in phase $\mathrm{B}$ the farmers must have their land be contiguous with the other group members. This group land requirement led to FGs within phase B being created and/or amended in, whereas in phase A the farmers were contracted in their preestablished group. These pre-existing FGs are voluntary groups and throughout all the communities, they fit the definition of collective action with a set of institutional rules and norms in place. By contracting farmers in groups during phase $\mathrm{B}$, the organizers also maintained existing collective action features by preserving community institutions, culture, and traditions. To explain in more detail, by contracting the farmers at the group level, they are making the PES more familiar to the participants as farmers traditionally throughout this region are organized into groups.

Phase A was deemed inefficient due to high compliance monitoring costs. Due to the farmers' plots being sporadically located throughout the landscape making it difficult to conduct random monitoring. To overcome this, a core aspect of phase B was the spatial proximity of the farmers' plots. This requirement made the scheme implementation and monitoring more efficient by reducing the costs to the facilitators. Furthermore, having all of the farmers lands in one area increases the environmental effectiveness of watershed protection (Banerjee, Cason, de Vries, \& Hanley, 2017).

\section{4 | Role of the farmer group}

As the farmers are contracted in one group (Data S1), the group organization and composition is important. All the PES contracted FGs have a group leader, secretary, and accountant, in line with the traditional FG structure. The leaders of the FG have a core role of liaising between the local NGO and the rest of the FG participants. In some cases, the FG leader may also be the village leader. Each group receives payments proportional with the total amount of hectares enrolled. The FG leaders receive this payment and decide, upon their discretion, to either withhold some money from group members (i.e., for community benefit projects or for group savings) or pay each farmer the total amount. Most FG leaders will withhold some money.

\section{5 | PES verification}

In both phases, farmers must maintain at least 500 trees/ha during the contract. If any trees are cut, the farmers must replant them. If there is a breach of contract by any one member of the FG, all members will receive a sanction with 
the possibility of the contract being terminated. Within the newer implementation phase $\mathrm{B}$, the PES contract requires the farmers to also undertake environmental management activities, resulting in Phase B farmers receiving a slightly higher payment (Table 1). These activities include reducing soil erosion through boreholes, livestock development, and home-industry activities. The compliance monitoring for phase A is manual, on-the-ground, and consists of verification and ground-checking on the farmers contracted land. Phase B monitoring is also manual and, in collaboration with ICRAF, the FKDC is developing remote monitoring processes using canopy density evaluations.

\section{3 | METHODS}

\section{1 | Data collection}

Two groups were identified for the surveys, participants in phase A $(n=87)$, and participants in phase B $(n=100)$. A participant list collected from Rekonvasi Bhumi was randomly sampled. The surveys (Data S6) were translated into Bahasa Indonesian by a native speaker familiar in PES and validated by two ICRAF researchers. A one-day training was organized for the enumerators of Rekonvasi Bhumi (local NGO), with the help of ICRAF, so that they were familiar with the content of the questionnaire to improve its accuracy. The surveys were completed in November 2016. The first day of data collection was removed as it was treated as a pilot survey. All scale/ranking questions were administered using meta-plan cards that were shown to each respondent. The numbers of the scale were demonstrated through unhappy to very happy smiley faces to ensure the respondent understood the intended answer.

In May 2017, we conducted follow-up focus group discussions (FGDs) to verify and interpret the findings from the previous survey and data analysis. We conducted four FGDs, two with phase A participants and two with phase B. Within these FGDs for each phase, one FGD was with the group leaders and the other FGD was for group members, approximately five to nine members were present in each FGD. This was to avoid the members being conditioned on their answers based on the FG leader. This is important as village leaders and elders have power dominance in decision making (Leimona, Jack, Lusiana, \& Pasha, 2010).

\subsection{Survey content and data}

Information on the individual farmer's demographics was collected. Including age, number of years of education, ethnicity, if their family helps on the plot, number of family members living in the house, do they have a second job, do they come from the area, do they have a loan, and what is their asset level (low, medium, high, breakdown in Data S2). Plot-level details were collected including area, tenure, what they produce, and if they have multiple farming plots.

Participants were first asked if they agree with a definition of fairness. This being - fair treatment or due rewards for all participants. Then once farmers had answered yes or no, they were then asked, bearing in mind the above definition, do they think the Cidanau PES scheme is overall fair (yes or no). We then gave the participants a definition of each dimension of equity (distributional, recognitional, procedural, and contextual) and asked them if they thought the scheme considered them (yes or no).

Data on the FGs' compliance was collected from the quarterly monitoring process supplied by the local NGO (Rekonvasi Bhumi). For this, we used the most recently collected data for all groups (November to December 2016). For the compliance and verification monitoring, the local NGO first randomly selects a few members from each group to check. Using these few members, they extrapolate their results to represent the entire group. Therefore, the data used within this analysis is at the group level and we follow the same assumption as the local NGO, which is that the select farmers are an adequate representation of the wider group.

We also collected data on if the farmers understood the PES, which was broken down into three components: understanding the PES purpose, understanding the PES action, and understanding what happens if they do not comply. These three components of understanding were categorized as low, medium or high levels of understanding based on their responses to a set list of choices (Data S3).

We asked all participants to answer questions regarding the scheme and their perceptions. These include, if they received enough information during the PES, if they received enough information before the PES to make an informed decision to join and if they feel that they need more information from the organizers. Within these questions, we also asked them to identify where they received the information for before the PES and during its implementation.

To assess perceptions of the PES contract, we first asked participants if they would prefer an individual-level contract rather than a group-level contract (i.e., receiving money directly rather than going through the FG). In addition, we asked farmers if they would like more money from the scheme. This could be interpreted as more money from the local NGO or more money from the FG, as some FGs set aside a small percentage of money for community development projects.

We measured the group cohesiveness of the FGs through the group environment questionnaire (GEQ) (Whitton \& 
Fletcher, 2014) which was modified to be applicable to the PES. We hypothesized that the group cohesiveness may be stronger in the first phase compared with the second. We also anticipate group cohesiveness to influence the participants understanding of the scheme and potentially their perceptions. Group cohesion has been found to influence success in other conservation programs (Gutiérrez et al., 2011).

The GEQ is an 18 question Likert scale survey (ranked $1=$ strongly disagree to $9=$ strongly agree) grouped of four main factors, 1, group integration-social (GI-S); 2, group integration-task (GI-T); 3, individual attractions to the group-social (ATG-S); and 4, individual attractions to the group—task (ATG-T). Group integration—social (GI-S) refers to a group member's sense of bonding as a social unit and closeness. Group integration-task (GI-T) relates to a group member's feelings towards the group's closeness and bonding over the group's task. Individual attractions to the group-social (ATG-S) relates to the group member's impressions of social connections and acceptance within the group. Individual attractions to the group-task (ATG-T) relates to the group member's feelings about their own involvement in the group's goals and productivity. In the dataset we sum the total value for each factor, taking into consideration the reverse scoring for some questions, treating each factor as continuous within the data analysis.

\section{3 | Data analysis}

All statistical analyses were completed using the R statistical environment ( $\mathrm{R}$ Core Team, 2017), all plots were created using the ggplot2 package (Wickham, 2009).

For our first aim, comparing fairness and compliance, we explore the descriptive statistics of farmers characteristics, perceived fairness, and level of compliance. For the second aim, exploring, the participants understanding and information, we first grouped the understanding questions by the FGs including where they have gotten information. We next ran an ordinal regression, using the ordinal package (Christensen, 2015), for each of the understanding variables (understanding the PES purpose, action, compliance, and the averaged variables) against the phase of the implementation, the farmer characteristics and plot data. For the third aim, perceptions of group level contact and group cohesiveness, we explore the descriptive data for both phase A and B.

For all models ran we tested interaction terms between phase and the farmer's characteristics to further capture potentially different responses between phases $\mathrm{A}$ and B. Using information theory and AIC we found the best fitting model. All models listed below represent the best fitting models.
T A B L E 2 Descriptive statistics of farmer characteristics and summary statistics of survey results

\begin{tabular}{|c|c|c|}
\hline Variable & $\begin{array}{l}\text { Phase A- } \\
\text { Social }(n=87)\end{array}$ & $\begin{array}{l}\text { Phase B- } \\
\text { Spatial }(n=100)\end{array}$ \\
\hline \multicolumn{3}{|l|}{ Characteristics } \\
\hline \multicolumn{3}{|c|}{ Average plot size (ha) } \\
\hline Min & 0.125 & 0.06 \\
\hline $\operatorname{Max}$ & 1.25 & 1.50 \\
\hline Mean & 0.45 & 0.70 \\
\hline \multicolumn{3}{|c|}{ Years of education } \\
\hline Min & 1 & 0 \\
\hline Max & 12 & 14 \\
\hline Mean & 5.9 & 6.55 \\
\hline \multicolumn{3}{|l|}{ Age } \\
\hline Min & 30 & 22 \\
\hline $\operatorname{Max}$ & 80 & 71 \\
\hline Mean & 49.94 & 45.63 \\
\hline \multicolumn{3}{|c|}{ Second job (\%) } \\
\hline Yes & 26 & 43 \\
\hline No & 74 & 57 \\
\hline \multicolumn{3}{|c|}{$\begin{array}{l}\text { Number of family } \\
\text { members }\end{array}$} \\
\hline Min & 0 & 0 \\
\hline Max & 8 & 9 \\
\hline Mean & 4.1 & 4.36 \\
\hline \multicolumn{3}{|l|}{ Loan $(\%)$} \\
\hline Yes & 1 & 7 \\
\hline No & 99 & 93 \\
\hline \multicolumn{3}{|c|}{ Asset category (\%) } \\
\hline Low & 23 & 18 \\
\hline Moderate & 64.4 & 70 \\
\hline High & 12.6 & 12 \\
\hline
\end{tabular}


T A B L E 2 (Continued)

\begin{tabular}{|c|c|c|}
\hline Variable & $\begin{array}{l}\text { Phase A- } \\
\text { Social }(n=87)\end{array}$ & $\begin{array}{l}\text { Phase B- } \\
\text { Spatial }(n=100)\end{array}$ \\
\hline Social & 15 & 14.7 \\
\hline Task & 11.5 & 11.5 \\
\hline \multicolumn{3}{|c|}{ Group integration } \\
\hline Social & 11.9 & 11 \\
\hline Task & 17.8 & 17 \\
\hline \multicolumn{3}{|c|}{$\begin{array}{l}\text { Perceptions of the group } \\
\text { contract }(\%)\end{array}$} \\
\hline \multicolumn{3}{|c|}{$\begin{array}{l}\text { Prefer individual level } \\
\text { contract (rather than } \\
\text { group level)? }\end{array}$} \\
\hline Yes & 7 & 16 \\
\hline No & 93 & 84 \\
\hline \multicolumn{3}{|c|}{$\begin{array}{l}\text { Want more money from } \\
\text { the scheme/farmer } \\
\text { group? }\end{array}$} \\
\hline Yes & 43 & 52 \\
\hline No & 57 & 48 \\
\hline
\end{tabular}

\section{4 | RESULTS}

\section{1 | Farmer characteristics, fairness, and compliance across phase A (social) and phase B (spatial)}

The average of farmer characteristics between each of the phases have some differences (Table 2). Phase B farmers have larger plot sizes, more education, are younger, and are

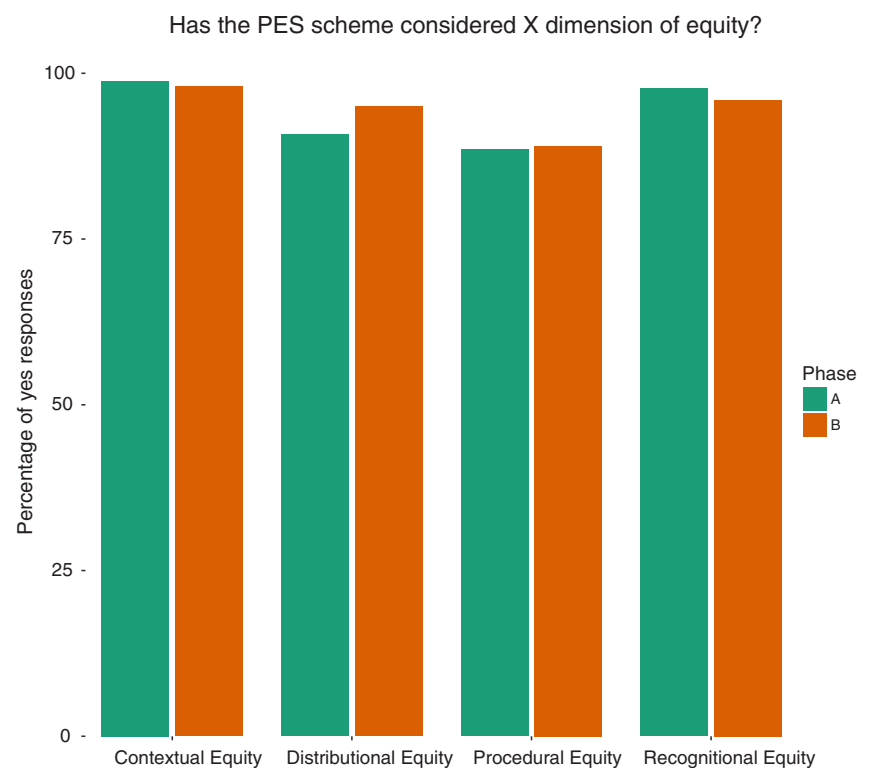

F I G URE 3 Distribution of respondent perception if the scheme has considered the dimensions of equity (contextual, distributional, procedural, and recognitional) across the two implementation phases
T A B L E 3 Compliance data at the group level

\begin{tabular}{lll} 
Phase & Farmer group & Verification (\%) \\
\hline A & Group 1 & 100 \\
& Group 2 & 190 \\
& Group 3 & 137.4 \\
& Group 4 & 115.4 \\
& Group 5 & 135.44 \\
B & Group 6 & 130 \\
& Group 7 & 126.72 \\
& Group 8 & - \\
& Group 9 & 132.88 \\
& Group 10 & 106.96 \\
& Group 11 & 102.25 \\
& Group 12 & 100 \\
\hline
\end{tabular}

Data corresponds to number of planted trees on farmer group plots during verification monitoring.

more likely to have a second job. Conversely, phase A farmers have smaller plot sizes, fewer years of education, are slightly older, and less likely to have a second job. Overall, the number of family members and the likelihood of having a loan are similar for both phases. We find that $99 \%$ of phase A and $100 \%$ of phase B participants agreed to the definition of fairness. For if the participants think the scheme is fair or not we find that $98 \%$ of phase A and 100\% of phase B, respectively, said yes. Overall, the participants think the scheme is considering each dimension of equity (Figure 3). The lowest proportion of yes responses was within procedural equity where both phases had 88.5 and $89 \%$, respectively. The largest difference between the Phase respondents was in distributional equity whereby Phase A had $90.8 \%$, yes and Phase B has 95\%. Neither contextual nor recognitional equity showed large differences between the two phases.

The compliance between the two PES phases was also similar (Table 3). The results indicate that some of the FGs were going beyond their compulsory actions, meaning that some farmers are planting over the total number of trees required on their plot. Some of the FGs were achieving over a 100\% compliance rate due to them planting more trees on their land and not cutting any down.

\subsection{PES understanding and information}

Within the analyses, we find that the understanding was similar between the two phases, aside from the understanding action model where phase B are more likely to understand (Figure 4, model tables in Data S4). All the understanding models showed, by contrast, a positive relationship with the group-integration to the task (GIT) variable. We also found 

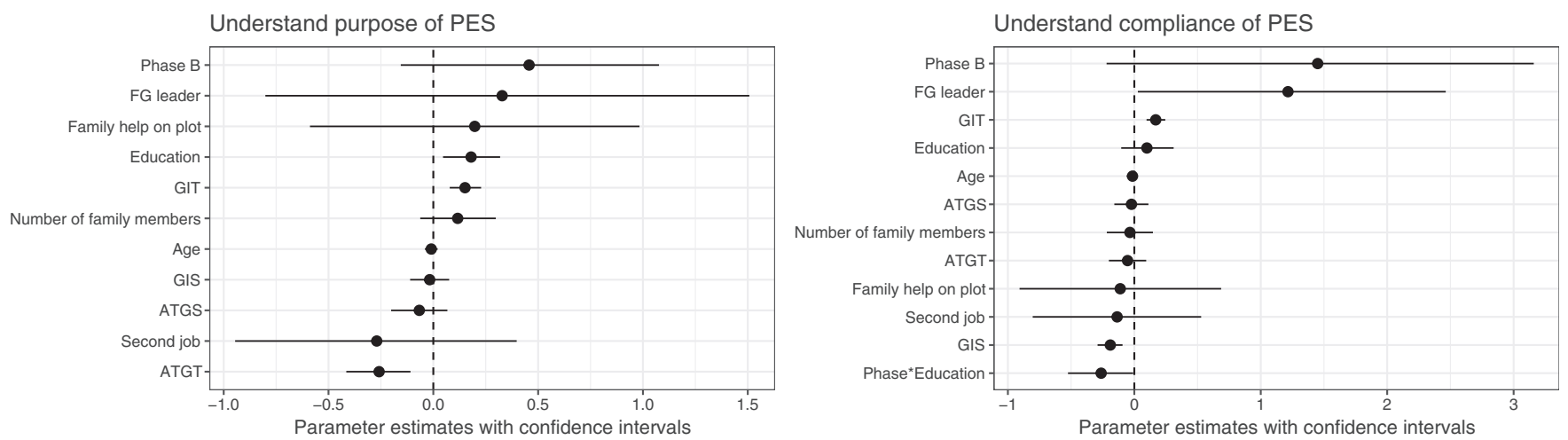

Parameter estimates with confidence intervals

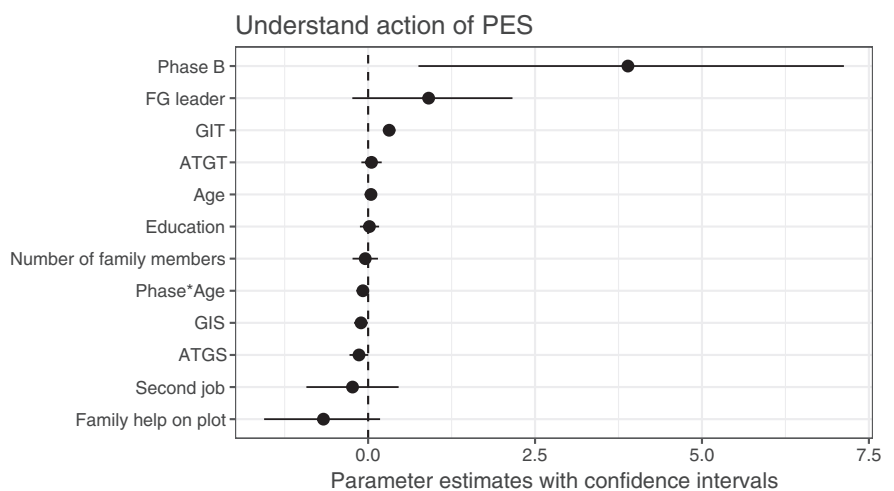

F I G URE 4 Ordinal regression model results for if they understand the purpose, if they understand compliance and if they understand the payments for ecosystem services action. GI-S, group integration—social; GI-T, group integration-task; ATG-S, individual attractions to the group—social; ATG-T, individual attractions to the group—task. Phase is categorical, comparing phase B to the base level of phase A

a positive relationship with the farmers' education and their understanding of the PES schemes purpose.

The information source for the participants, both before the scheme was implemented and during the schemes implementation process, was varied (Data S5). For phase A, information before the PES implementation is mixed between the local NGO (Rekonvasi Bhumi), the village chairman, and the leader of the FGs. With the majority of information during the scheme implementation being from the FG leaders. For phase B we found a slightly different scenario before the PES was implemented the information was mainly from the local NGO and during the implementation the information is from either the village chairman or the FG leader. It is important to highlight the differences between the village chairman and FG leader. Within some of the FGs (i.e., Harapanjaya), the FG leaders are also village leaders. Due to this, disentangling the information source can be convoluted; ultimately, we treat the village chairman and FG leaders as the same group of individuals.

For the participant's perceptions of the group level contract, we find that the phase B group are more likely to want individual level contracts (16\% said yes) compared to the phase A group (7\% said yes). However, we do see similarities between if the farmers want more money from the scheme. Building on this, the group cohesiveness measures shows similarities between the phases for individual attractions to the group both social and task. Whereas, in phase A we find that they have a higher ranking for group integration social and task. This indicates that phase A participants, at the group level, are more integrated both socially and through the task at hand (contracted into the PES scheme) compared to the phase B participants.

\section{5 | DISCUSSION}

Our results indicate that both the social (phase A) and spatial targeting (phase B) of participants was fair, and all participants were complying. We find positive outcomes through perceived fairness and high level of compliance, which we hypothesize is due to strong group cohesiveness and through engaging existing social institutions. Furthermore, our results highlight that the group level organizational structure could be overcoming the lack of knowledge/understanding of the PES scheme, which subsequently is ensuring that the environmental objectives are met.

\section{1 | Fairness and compliance}

We find that the participants in the PES scheme, throughout both phase A and phase B find the scheme to be overwhelmingly fair and equitable across the equity dimensions. The 
PES organizers decision to make the implementation more efficient through spatial targeting appears to have minimal negative impacts on perceptions of fairness. Some PES schemes with government involvement, have been criticized for emphasizing social benefits over environmental effectiveness (Ezzine-de-Blas, Dutilly, Lara-Pulido, Velly, \& Guevara-Sanginés, 2016). We find that prioritizing environmental effectiveness, in combination with reducing implementation costs, can be both efficient and fair. In contrast, equity-efficiency trade-offs are often highlighted within the PES literature (García-Amado, Pérez, Escutia, García, \& Mejía, 2011; Pascual, Muradian, Rodriguez, \& Duraiappah, 2010; Wu \& Yu, 2017). This is important in PES implementation as communities with strong existing social institutions may be more conducive to establishing a PES program that builds upon these foundations, as with phase A.

Implementers for the phase A contracted pre-existing FGs to be participants. Whereas in phase B, the spatial proximity land requirement led to FG being created and/or amended for their participation. Due to this difference, we anticipated disparities in group perceptions of fairness and compliance levels, as these are influenced by group cohesiveness. One explanation of the similarities between phases $\mathrm{A}$ and $\mathrm{B}$ is through high levels of social capital within these communities (McGrath et al., 2018). High levels of social capital can influence the success and outcomes of PES programs. Further to this, the implementers of the PES purposely selected to contract at the group level, as this was in line with the rules, norms, and culture of the communities. Therefore through engaging participants through existing institutions (i.e., FGs and high social capital) we found no differences between the implementation phases as noted in personal observations and the focus group discussions. Importantly, research has found that more generic PES schemes fail to recognize the culture and cohesive function of communities (Boelens, Hoogesteger, \& de Francisco, 2014) and that they must be malleable to adapt to diverse local norms and traditions.

Further, all FGs are complying with the PES scheme and in some cases going beyond what is required (Table 2), meaning more trees are planted than necessary to fulfill the PES requirement. This over exceeding may be a reflection of the culture where trees are often used as a guarantee if the farmers need to borrow money. It could be that because the farmers are not allowed to cut their trees based on the PES contract, they are planting more to be used as a future guarantee. In addition, belonging to a group and the strong social cohesiveness could further explain the exceptionally high levels of compliance, and as aforementioned the Cidanau PES site has high levels of social capital across the community (McGrath et al.,
2018). Narloch et al. (2017) find that group level contracts may be an incentive for compliance.

\subsection{PES understanding and information}

We find that the participant understanding of the scheme is mixed, despite finding that all farmers are complying or over complying (Table 3). This is in line with previous research within the Cidanau PES, Lapeyre et al. (2015) list the possible reasons for this as low education and insufficient capacity of FG leaders. We find that education did not act as a barrier to the farmers understanding of the action and compliance, rather it is important for understanding the PES purpose. Throughout the results, we find that the group cohesiveness explains a proportion of the farmers understanding. More specifically, results indicate that groups that have a higher group integration over the task (GI-T) have a higher understanding of the PES scheme's purpose, what they are supposed to do in the PES scheme, and what happens if they do not comply. This means that individuals who have a positive perception of the closeness and similarity within the group about accomplishing the task, are more likely to understand the PES scheme. This result could also be explained by the "tanggung renteng" or joint responsibility initiative that the local NGO put forth during the scheme implementation. Furthermore, we find that understanding of compliance and of the purpose of the scheme shows no obvious correlation to the participant's phase. We find that phase $B$ has a better understanding of the contractual obligations compared to phase A. This difference in understanding may be due to phase $\mathrm{B}$ having to complete the proposal more recently and the local NGO had more intensive group facilitation with FGs in this phase.

The source of the information for the participants highlights an important point of power and leadership. Noted by Lauber, Decker, and Knuth (2008), transfers of knowledge and communication in resource management schemes usually involve a person in a position of power. In fisheries management, it has been found that leadership is a critical feature to promote success (Gutiérrez et al., 2011). Building on this, leadership roles based on respect and clarity of responsibilities can improve the likelihood of participants understanding the project aims (Dyer et al., 2014). This highlights the importance of ensuring that the FG leaders are well informed and can accurately/successfully disseminate information to their group members.

\section{3 | Engaging with existing institutions- Contracting at the group level}

The majority of participants indicated they do not want more money from the PES scheme. As aforementioned, one possi- 
ble reason for this is that the farmers were unsure if having more money meant less for the community projects their FG contributes to, or if it would direct from the PES organizers. Another explanation is that the FG members do not heavily rely on the PES payment for any other than daily household expenses, as indicated in the focus group discussions. Within the PES literature, there are debates about if the payments given to participants are additional to what they would have done without the incentive (Kerr et al., 2014). The result that most farmers do not want more money and that the PES payment is enough to cover daily household expenses leads, to some questions about if the scheme is truly additional. This was explored in more detail by Lapeyre et al. (2015) who state that the additionality of the scheme may not have been verified and the current situation suggests that the PES organizers place their priorities on number of participants, even in the absence of additional ecosystem service delivery. However, beyond this, no further research has been completed and is unknown at this stage within this scheme.

We find that participants in phase B are more likely to want an individual payment compared to those in phase A, however, the overwhelming majority of both phases prefer a group level contract. Narloch et al. (2017) find that working with strong collective action provides an incentive towards group payments rather than individual payments. As evident in other research at Cidanau we know that the FGs and the wider community have high levels of social capital (McGrath et al., 2018), potentially explaining why the farmers prefer group level contracts. Furthermore, contracting the farmers in groups allows for more opportunities to learn and discuss with each other (Narloch et al., 2017), which may increase the successfulness of the conservation outcomes. The Cidanau PES appears to match the conditions for successful collective action (Agrawal, 2002) as suggested by Kaczan, Pfaff, Rodriguez, and Shapiro-Garza (2017), whereby the scheme is reinforcing existing governance mechanisms through the use of FGs. Collective contracting of PES participants can suffer from free riding which can undermine the objectives of the scheme (Kaczan et al., 2017). Within the Cidanau PES scheme, we hypothesize that this may not be the case, as the farmers are faced with random compliance monitoring. If a group member is found not to be complying the entire group will be reprimanded and face expulsion from the scheme. The scheme implementers experienced this with two FGs who were subsequently removed from the PES scheme in 2008 and 2009, respectively, for non-compliance of only a few group members. These group members were said to be the "rich men" of the villages, who did not care about the payments. Furthermore, Midler, Pascual, Drucker, Narloch, and Soto (2015) explore in the Peruvian Andes that collective rewards may be more sensitive to social factors and have the potential to be less effective. These social factors, such as social ties and communication were also identified in the Cidanau PES scheme. Whereby high levels of social capital may have led to some farmers to feel pressured into participating in the PES scheme (Lapeyre et al., 2015).

The methods and results of this manuscript are not without limitation. One limitation is that due to data collection methods and low literacy rate; the enumerators read each question and asked the respondent for their answer. This can lead to response bias with the enumerator interpreting what the respondent is saying, particularly with scale questions. To overcome this we created a scale of smiley faces printed on paper for respondents to view and select which one corresponded to their answer. Further, another limitation is that the data is a snapshot of one point in time, which ignores potential trends of perceptions over time. In addition, one limitation is that all of the PES contracted farmers worked in groups. Future research could investigate schemes where groups and individuals are hired. This would allow testing whether group social cohesion plays a role on the high compliance levels observed.

\section{6 | CONCLUSIONS}

We find that both social and spatial targeting of participants is equitable, with all FGs fulfilling their compliance target. Furthermore, we find that the group level organizational structure could be overcoming the lack of knowledge/understanding of the PES scheme, which subsequently is ensuring that the environmental objectives are met. We found that education is not the main variable influencing how much the participants understand the scheme. Instead, social factors, such as group cohesiveness, are more important. This has implications for PES implementation. Currently, the status quo would be to explicitly engage those with less capacity. On the other hand, in some scenarios, the time would be better spent engaging with those who are social outliers, who may not be those with less capacity. This perhaps is more important when contracting at the group level but may still have implications for contracting at the individual level.

Based on the results from this research we have general recommendations for PES practitioners. Spatial targeting (identifying participants based on their plot location) at the group level can be both efficient and fair if PES proponents work within the existing institutions. Engaging in these existing institutions can ensure that the potential negative social impacts of the PES are mediated. Further, information quality, quantity, and transparency are key. Ensuring that all participants understand is crucial to the scheme's success. If contracting at the group level, facilitators should make sure that the group leaders are well educated in the scheme and its 
details. Furthermore, group level contracts may aid in information dissemination between group members, potentially reducing the potential time spent by facilitators doing so.

\section{ACKNOWLEDGEMENTS}

F.M. would like to thank the Rufford Small Grant for Nature Conservation for funding the data collection and the Singapore International Graduate Award (SINGA) for funding the $\mathrm{PhD}$ stipend at the National University of Singapore. All authors would like to thank the survey participants throughout the Cidanau watershed.

\section{CONFLICT OF INTEREST}

The authors have no conflicts of interest to declare.

\section{AUTHOR CONTRIBUTIONS}

F.L.M. lead the research design, implementation, data analysis, and paper writing with contributions from L.R.C., B.L., S.A. and N.P.R.

\section{DATA ACCESSIBILITY}

Due to the sensitive nature of the compliance data, this will remain confidential. For all other data in the article please contact the lead author for access.

\section{ETHICS STATEMENT}

This study was conducted with the IRB approval from the National University of Singapore obtained in August 2016 (approval NUS-IRB Ref: B-16-146, certificate: NUS 3087). The Indonesian permit application process took place between August and October 2016 (number: 2744/FRP/E5/ Dit.KI/X/2016). All participants gave verbal consent to partake in the data collection with personal information redacted.

\section{ORCID}

Francesca L. McGrath (1) https://orcid.org/0000-0002-7159$856 \mathrm{X}$

\section{REFERENCES}

Abrahamse, W., \& Steg, L. (2013). Social influence approaches to encourage resource conservation: A meta-analysis. Global Environmental Change, 23, 1773-1785. https://doi.org/10.1016/j.gloenv cha.2013.07.029
Agrawal, A. (2002). Common resources and institutional sustainability, the drama of the commons. Washington, DC: National Academy Press.

Agrawal, A., \& Ostrom, E. (2001). Collective action, property rights, and decentralization in resource use in India and Nepal. Politics and Society, 29, 485-514. https://doi.org/10.1177/0032329201029 004002

Amaruzaman, S., Rahadian, N. P., Leimona, B. (2017). Role of intermediaries in the payment for environmental services scheme: Lessons learnt in the Cidanau watershed, Indonesia. Co-Investment in Ecosystem Services: Global Lessons from Payment and Incentive Schemes. World Agroforestry Centre (ICRAF).

Angelsen, A., Brockhaus, M., Kanninen, M., Sills, E., Sunderlin, W. D., \& Wertz-Kanounnikoff, S. (Eds.). (2009). Realising REDD+: National strategy and policy options. Bogor: Center for International Forestry Research (CIFOR). https://doi.org/ 10.17528/cifor/002871

Angelsen, A., Brockhaus, M., Sunderlin, W. D., Verchot, L. (2012). Analysing REDD+: Challenges and choices. Center for International Forestry Research. Bogor, Indonesia: Center for International Forestry Research (CIFOR).

Arifin, B. (2005). Institutional constraints and opportunities in developing environmental service markets: Lessons from institutional studies on RUPES in Indonesia.

Banerjee, S., Cason, T. N., de Vries, F. P., \& Hanley, N. (2017). Transaction costs, communication and spatial coordination in payment for ecosystem services schemes. Journal of Environmental Economics and Management, 83, 68-89. https://doi.org/10.1016/j. jeem.2016.12.005

Boelens, R., Hoogesteger, J., \& de Francisco, J. C. R. (2014). Commoditizing water territories: The clash between Andean water rights cultures and payment for environmental services policies. Capitalism Nature Socialism, 25, 84-102. https://doi.org/10.1080/ 10455752.2013.876867

Börner, J., Baylis, K., Corbera, E., Ezzine-de-Blas, D., HoneyRosés, J., Persson, U. M., \& Wunder, S. (2017). The effectiveness of payments for environmental services. World Development, 96, 359-374. https://doi.org/10.1016/j.worlddev.2017.03.020

Bremer, L. L., Farley, K. A., \& Lopez-Carr, D. (2014). What factors influence participation in payment for ecosystem services programs? An evaluation of Ecuador's SocioParamo program. Land Use Policy, 36, 122-133. https://doi.org/10.1016/j.landusepol. 2013.08.002

Budhi, G. S., Sa, K., \& Iqbal, M. (2016). Concept and implementation of Pes program in the Cidanau watershed: A lesson learned for future environmental policy. Anal Kebijak Pertan, 6, 37-55. https:// doi.org/10.21082/akp.v6n1.2008.37-55

Christensen, R. H. B. (2015). Ordinal: Regression models for ordinal data. Retrieved from https://cran.r-project.org/web/packages/ ordinal/index.html

de Koning, F., Aguinaga, M., Bravo, M., Chiu, M., Lascano, M., Lozada, T., \& Suarez, L. (2011). Bridging the gap between forest conservation and poverty alleviation: The Ecuadorian socio Bosque program. Environmental Science \& Policy, 14, 531-542. https:// doi.org/10.1016/j.envsci.2011.04.007

Dyer, J., Stringer, L. C., Dougill, A. J., Leventon, J., Nshimbi, M., Chama, F., ... Syampungani, S. (2014). Assessing participatory practices in community-based natural resource management: Experiences in community engagement from southern Africa. Journal of 
Environmental Management, 137, 137-145. https://doi.org/10. 1016/j.jenvman.2013.11.057

Ezzine-de-Blas, D., Dutilly, C., Lara-Pulido, J.-A., Velly, G. L., \& Guevara-Sanginés, A. (2016). Payments for environmental services in a Policymix: Spatial and temporal articulation in Mexico. PLoS One, 11, e0152514. https://doi.org/10.1371/journal.pone.0152514

Fisher, J. (2012). No pay, no care? A case study exploring motivations for participation in payments for ecosystem services in Uganda. Oryx, 46, 45-54. https://doi.org/10.1017/S0030605311001384

García-Amado, L. R., Pérez, M. R., Escutia, F. R., García, S. B., \& Mejía, E. C. (2011). Efficiency of payments for environmental services: Equity and additionality in a case study from a Biosphere Reserve in Chiapas, Mexico. Ecological Economics, 70, 2361-2368. https://doi.org/10.1016/j.ecolecon.2011.07.016

Gutiérrez, N. L., Hilborn, R., \& Defeo, O. (2011). Leadership, social capital and incentives promote successful fisheries. Nature, 470, 386-389. https://doi.org/10.1038/nature09689

Hayes, T., \& Murtinho, F. (2018). Communal governance, equity and payment for ecosystem services. Land Use Policy, 79, 123-136. https://doi.org/10.1016/j.landusepol.2018.08.001

Jost, F., \& Gentes, I. (2014). Payment schemes for environmental services: Challenges and pitfalls with respect to effectiveness, efficiency and equity. In J. Pretzsch, D. Darr, H. Uibrig, \& E. Auch (Eds.), Forests and rural development, Tropical Forestry (Vol. 9, pp. 241-263). Berlin, Germany: Springer.

Kaczan, D., Pfaff, A., Rodriguez, L., \& Shapiro-Garza, E. (2017). Increasing the impact of collective incentives in payments for ecosystem services. Journal of Environmental Economics and Management, 86, 48-67. https://doi.org/10.1016/j.jeem.2017.06.007

Kerr, J. M., Vardhan, M., \& Jindal, R. (2014). Incentives, conditionality and collective action in payment for environmental services. International Journal of the Commons, 8, 595-616.

Kosoy, N., Corbera, E., \& Brown, K. (2008). Participation in payments for ecosystem services: Case studies from the Lacandon rainforest, Mexico. Geoforum, Placing Splintering Urbanism, 39, 2073-2083. https://doi.org/10.1016/j.geoforum.2008.08.007

Lapeyre, R., Pirard, R., \& Leimona, B. (2015). Payments for environmental services in Indonesia: What if economic signals were lost in translation? Land Use Policy, 46, 283-291. https://doi.org/10.1016/ j.landusepol.2015.03.004

Lauber, T. B., Decker, D. J., \& Knuth, B. A. (2008). Social networks and community-based natural resource management. Environmental Management, 42, 677-687. https://doi.org/10.1007/s00267-0089181-8

Leimona, B., Jack, B. K., Lusiana, B., Pasha, R. (2010). Designing a procurement auction for reducing sedimentation: A field experiment in Indonesia (EEPSEA Research Report No. rr2010042). Economy and Environment Program for Southeast Asia (EEPSEA).

Leimona, B., Pasha, R., \& Rahadian, N. P. (2010). The livelihood impacts of incentive payments for watershed management in Cidanau Watershed, West Java, Indonesia. In L. Tacconi, S. Mahanty, \& H. Suich (Eds.), Payments for environmental services, forest conservation and climate change: livelihoods in the REDD? (pp. 106-129). Cheltenham, UK: Edward Elgar Publishing.

Leimona, B., van Noordwijk, M., de Groot, R., \& Leemans, R. (2015). Fairly efficient, efficiently fair: Lessons from designing and testing payment schemes for ecosystem services in Asia. Ecosystem Services, 12, 16-28. https://doi.org/10.1016/j.ecoser.2014.12.012
Mahanty, S., Suich, H., \& Tacconi, L. (2013). Access and benefits in payments for environmental services and implications for REDD+: Lessons from seven PES schemes. Land Use Policy, 31, 38-47. https://doi.org/10.1016/j.landusepol.2011.10.009

Martin, A., Gross-Camp, N., Kebede, B., \& McGuire, S. (2014). Measuring effectiveness, efficiency and equity in an experimental payments for ecosystem services trial. Global Environmental Change: Human and Policy Dimensions, 28, 216-226. https://doi.org/10. 1016/j.gloenvcha.2014.07.003

Martin, A., Gross-Camp, N., Kebede, B., McGuire, S., \& Munyarukaza, J. (2014). Whose environmental justice? Exploring local and global perspectives in a payments for ecosystem services scheme in Rwanda. Geoforum, 54, 167-177. https://doi.org/10. 1016/j.geoforum.2013.02.006

McGrath, F., Erbaugh, J., Leimona, B., Amaruzaman, S., Rahadian, N., \& Carrasco, L. R. (2018). Green without envy: How social capital alleviates tensions from a payments for ecosystem services (PES) program in Indonesia. Ecology and Society, 23. https://doi.org/10.5751/ES-10181-230410

Midler, E., Pascual, U., Drucker, A. G., Narloch, U., \& Soto, J. L. (2015). Unraveling the effects of payments for ecosystem services on motivations for collective action. Ecological Economics, 120, 394-405. https://doi.org/10.1016/j.ecolecon.2015.04.006

Murtinho, F., \& Hayes, T. (2017). Communal participation in payment for environmental services (PES): Unpacking the collective decision to enroll. Environmental Management, 59, 939-955. https:// doi.org/10.1007/s00267-017-0838-z

Narloch, U., Drucker, A. G., \& Pascual, U. (2017). What role for cooperation in conservation tenders? Paying farmer groups in the high Andes. Land Use Policy, 63, 659-671. https://doi.org/10.1016/j. landusepol.2015.09.017

Okten, C., \& Osili, U. O. (2004). Social networks and credit access in Indonesia. World Development, 32(7), 1225-1246.

Ostrom, E. (1990). Governing the commons: The evolution of institutions for collective action. Cambridge: Cambridge University Press.

Pascual, U., Muradian, R., Rodriguez, L. C., \& Duraiappah, A. (2010). Exploring the links between equity and efficiency in payments for environmental services: A conceptual approach. Ecological Economics, 69, 1237-1244. https://doi.org/10.1016/j.ecolecon.2009. 11.004

Pascual, U., Phelps, J., Garmendia, E., Brown, K., Corbera, E., Martin, A., ... Muradian, R. (2014). Social equity matters in payments for ecosystem services. BioScience, 64, 1027-1036. https:// doi.org/10.1093/biosci/biu146

Petheram, L., \& Campbell, B. M. (2010). Listening to locals on payments for environmental services. Journal of Environmental Management, 91, 1139-1149. https://doi.org/10.1016/j.jenvman.2010. 01.002

R Core Team. (2017). R: A language and environment for statistical computing. Vienna: R Foundation for Statistical Computing.

Sommerville, M., Milner-Gulland, E. J., Rahajaharison, M., \& Jones, J. P. G. (2010). Impact of a community-based payment for environmental services intervention on Forest use in Menabe, Madagascar. Conservation Biology, 24, 1488-1498. https://doi.org/10. 1111/j.1523-1739.2010.01526.x

Whitton, S. M., \& Fletcher, R. B. (2014). The group environment questionnaire a multilevel confirmatory factor analysis. Small Group Research, 45, 68-88. https://doi.org/10.1177/1046496413511121 
Wickham, H. (2009). ggplot2: Elegant graphics for data analysis. New York, NY: Springer-Verlag.

Wu, J., \& Yu, J. (2017). Efficiency-equity tradeoffs in targeting payments for ecosystem services. American Journal of Agricultural Economics, 99, 894-913. https://doi.org/10.1093/ajae/aaw095

Wünscher, T., Engel, S., \& Wunder, S. (2008). Spatial targeting of payments for environmental services: A tool for boosting conservation benefits. Ecological Economics, 65, 822-833. https://doi.org/10. 1016/j.ecolecon.2007.11.014

Zanella, M. A., Schleyer, C., \& Speelman, S. (2014). Why do farmers join payments for ecosystem services (PES) schemes? An assessment of PES water scheme participation in Brazil. Ecological Economics, 105, 166-176. https://doi.org/10.1016/j.ecolecon.2014. 06.004

\section{SUPPORTING INFORMATION}

Additional supporting information may be found online in the Supporting Information section at the end of this article.

How to cite this article: McGrath FL, Leimona B, Amaruzaman S, Rahadian NP, Carrasco LR.

Identifying payments for ecosystem services participants through social or spatial targeting?

Exploring the outcomes of group level contracts.

Conservation Science and Practice. 2019;1:e49.

https://doi.org/10.1111/csp2.49 